GLOBAL MEDICAL ETHICS

\title{
Community based trials and informed consent in rural north India
}

\author{
A DeCosta, N D'Souza, S Krishnan, M S Chhabra, I Shihaam, K Goswami
}

J Med Ethics 2004;30:318-323. doi: 10.1136/ime.2002.001065

Disease control has increasingly shiffed towards large scale, disease specific, public health interventions. The emerging problems of HIV, hepatitis, malaria, typhoid, tuberculosis, childhood pneumonia, and meningitis have made community based trials of interventions a cost effective long term investment for the health of a population. The authors conducted this study to explore the complexities involved in obtaining informed consent to participation in rural north India, and how people there make decisions related to participation in clinical research.

See end of article for authors' affiliations .....................

Correspondence to: M S Chhabra, Room 17, Hostel 7, All India Institute of Medical Sciences, New Delhi 11029, India; manpreetch@yahoo.com

Received 21 June 2002 Accepted 2 June 2003
$\mathrm{T}$ he public health intervention needs of developing countries vary substantially from those of developed regions. Many countries in the developing world are now sites of field testing of biomedical agents to provide answers to these substantial public health problems.

However, field clinical investigations in developing societies like India take place within particular contexts of regional values and practices, local concepts of disease (and health), and power hierarchies in the family/village that constitute local cultural systems. Obtaining ethical and meaningful informed consent for clinical studies conducted in these settings becomes more challenging because of cultural differences between Western clinical research ethics and local customs and practices prevalent in the developing world.

It has often been debated as to whether research ethics should be adapted to the cultural values of a local community. ${ }^{12}$ Some authors suggest a community based approach to enrolment wherein the decision regarding participation is taken by the village/community leader, ${ }^{3}$ as befits some societies in the developing world where decisions are taken at the community level rather than that of the individual. There has been much discussion of concepts such as the "culturally relevant" or "culturally sensitive" application of Western medical ethics to research in developing countries ${ }^{4}$ as other authors believe that adaptation of Western ethical standards to different cultural settings may allow for exploitation in the developing world.

We conducted this study to explore the consent to participation in rural north India; how people there make decisions related to participation in clinical research:

- Who decides about a subject's consent? complexities involved in obtaining informed
- Would they allow their children to participate?

- What kind of information would they wish to know from the physician/investigator?

- What would be the motives for participation/ non-participation?

The answers to these questions have become increasingly important in the light of an increasing number of biomedical interventions undergoing human trials in the developing world.

\section{MATERIALS AND METHODS \\ Study setting}

Our study was conducted in Chhainsa, a village in Haryana state of northern India, about $75 \mathrm{kms}$ from New Delhi. The majority of its 6000 strong population is Hindu and speaks the Haryanvi dialect of the national language, Hindi. Literacy levels in this population vary from $74.7 \%$ for males and $49.3 \%$ for females. ${ }^{5}$ Agriculture is the main occupation and involves men and women intensively.

Chhainsa is one of the villages served by the Comprehensive Rural Health Services Project (CRHSP), Ballabgarh, of the All India Institute of Medical Sciences (AIIMS).

\section{Study design}

An interview schedule was designed to be administered in the local language, Hindi. The purpose of the interview was to elicit the views of the inhabitants of Chhainsa village regarding their participation in community based clinical research, if the same were to be conducted in their village. Chhainsa's population of 6000 is divided into nine to 10 mohullas (localities) based on social caste. In order to administer the interview, every 20th house was selected systematically, the first house being selected randomly using a currency note. The youngest available married male or, if unavailable, the youngest married female in each household was interviewed. This decision was taken as women are not the predominant decision makers in the family in matters concerning their own or their children's health, ${ }^{5}$ society in this region being strongly patriarchal. As most of the households in the study area consist mainly of three generation families living together, the youngest married male (or married female) was selected to obtain a response from a representative of the breadwinning couple (which supports the other two generations), who would be in the reproductive age group, and whose wife, child, or self are most likely to be potential subjects for clinical research in a developing setting. The interview 
schedule was developed in English, translated into the local language, and validated by back translation. Multiple tests before beginning the study were conducted in a similar setting outside the study area before finalisation of the study instrument. As seen during this initial stage, most people in the community had not heard of clinical research. They had also not heard of volunteers for research involving healthy human subjects-that is, about healthy subjects voicing their opinions on health related matters during an interview survey, giving a blood sample, or taking a vaccine or drug as part of a trial.

Keeping in mind the above lack of knowledge, the concept and need for health related community based research on healthy human subjects was introduced in Hindi to each participant as follows after he/she had given consent to participate in our interview: "Sometimes complete information is not available to prevent or treat certain health related conditions that occur in our communities and often one has to develop better knowledge/new modalities of treatment for these conditions. It is either to prevent or treat such conditions that research is conducted. This research may involve apparently healthy members of your community answering questions, giving a blood sample, taking a drug, or a vaccine. Each member of the community is free to decide if he/she would like to take part"

The interview was structured around a given hypothetical scenario in which a community based clinical investigation was to be planned in Chhainsa. Subjects were informed that the intervention could include either a simple interview, giving a blood sample, having a vaccine, or taking a new drug. The interview was framed to elicit answers (open ended) to the following questions:

1. Would the subject be willing to participate in the study?

2. Who would decide about whether the subject should participate/not participate in the study?

3. How would the decision maker arrive at his/her decision?

4. What would be the subject's reasons for participation/ non-participation?

5. Would the subject's child be allowed to participate in the study?

6. If the subject's child were to be enrolled, who would decide about whether the child should participate or not?

7. Why would the decision maker allow/disallow the subject's child's participation?

8. What information would the subject like to know before volunteering himself for such community based research?

The answers were recorded directly onto the interview schedule in Hindi. The interviews were conducted by doctors working in the area who were fluent in the language.

\section{Data analysis}

The answers to the open ended questions were manually coded after data collection was complete. The data was then entered into a microcomputer using DBASE III plus (DBASE Inc, New York, USA) and analysed using EPI INFO version 6 (from the Centers for Disease Control and Prevention). Some of the results were presented graphically using Microsoft Excel.

\section{RESULTS}

\section{Sociodemography}

Fifty nine households were visited, of which 57 participated (96.6\% participation rate). The families who refused to participate felt that they would not benefit in any way from their participation in the study. Of the fifty seven subjects interviewed, $50(87.7 \%)$ were male. The mean age of the subjects was 31.2 years (range $18-58$ years). Forty five $(78.9 \%)$ of the subjects were literate (at least primary education). $70.2 \%$ belonged to joint families while the remaining lived in nuclear families. All study participants were Hindus except for one Sikh. Thirty two (56.1\%) were agriculturists, eight (14\%) were shopkeepers, five $(8.8 \%)$ were daily wagers (unskilled manual labourers performing seasonal agricultural tasks), four (7\%) were housewives, and the remaining eight were either teachers, government employees, tailors, students, or mechanics.

\section{Would the subject be willing to participate in the study?}

Although most of the subjects interviewed were willing to participate in the study, their willingness varied depending upon the type of the proposed intervention. As can be seen in figure 1 , the subjects were more willing to participate if the intervention involved answering an interview (56 of 57, or $98.2 \%$ ) or giving a blood sample (49 of 57 , or $86 \%$ ) than if it involved being administered a vaccine ( 36 of 57 , or $63.2 \%$ ) or a drug (38 of 57 , or $66.7 \%$ ).

\section{Who decides about the subject's participation?}

Of the 50 men interviewed, 45 (90\%) reported themselves to be decision makers regarding their own participation. The remaining five men $(10 \%)$ reported elder members of their extended families as deciding for them-either a father, both parents, or an elder brother.

Three of the seven women $(42.8 \%)$ interviewed said that they would decide for themselves. Two said that their husbands would decide and another two women said that their mother-in-law would decide if they should participate in the research.

\section{How would the decision maker arrive at his/her} decision regarding participation?

Of the 45 males who reported themselves to be decision makers, $20(44.4 \%)$ said they would decide without consulting anyone else and 19 men $(42.2 \%)$ said they would consult their family members. Three men said they would need to consult their friends and another three needed to consult their friends and neighbours in the village. The five men who reported an older family member as being the decision maker were unaware of how that member would decide (by himself or in consultation with others) but would abide by his decision nevertheless. On being asked how the elder member

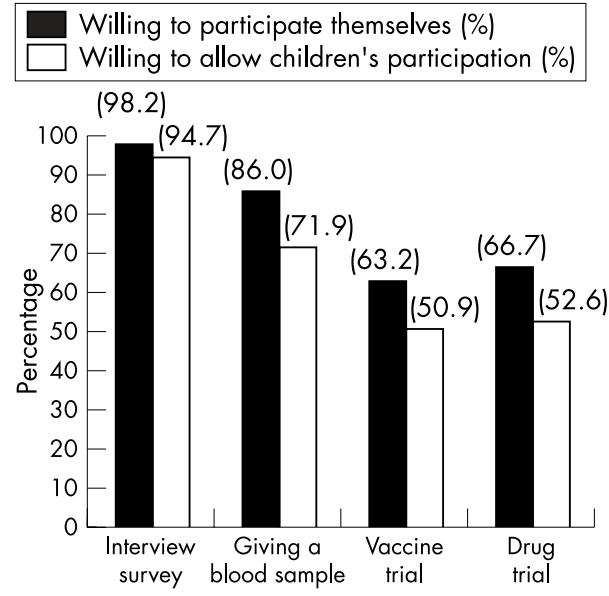

Figure 1 Willingness for participation in research studies $(n=57)$. 
of the family would reach a decision, one of these men replied, "I do not know. Only he will know how he decides".

of the seven women interviewed, only one who was the head of the household said she would decide alone. The remaining six would decide in consultation with their families.

What are the reasons for the subject's participation/ non-participation?

Participation

Altruism (benefiting others and furthering medical knowledge) emerged as the commonest stated motivating factor for participation in a community based research study involving any of the mentioned interventions (an interview survey, giving a blood sample, taking a vaccine or a drug). However, as figure 2 shows, subjects were more wary of the latter three interventions. Another important reason for participation was an implicit faith in doctors and the medical system. One subject responded, "Doctors will not give us anything that is harmful". Another subject said, "Doctors are in a way godly. Who would know better than them?" Other motives for participation cited were money, opportunity to get know of illnesses one is harbouring (through blood tests), or "having nothing to lose".

\section{Non-participation}

Subjects were most reluctant to participate in a vaccine or drug trial (fig 1) for fear of the unknown adverse effects as seen from table 1 . One subject responded, "Why should I take a medicine which is unknown?"

Some of the subjects interviewed did not feel any need to participate, as they perceived themselves as "well". A few of the subjects were also reluctant to give a blood sample. One woman exhorted her husband while we were interviewing him, "They'll take a lot of blood from you. Don't give them any. Don't even tell them your name." Some subjects cited the indigenous belief of "khoon ki kami", or having a volumetric deficiency of blood in one's body.

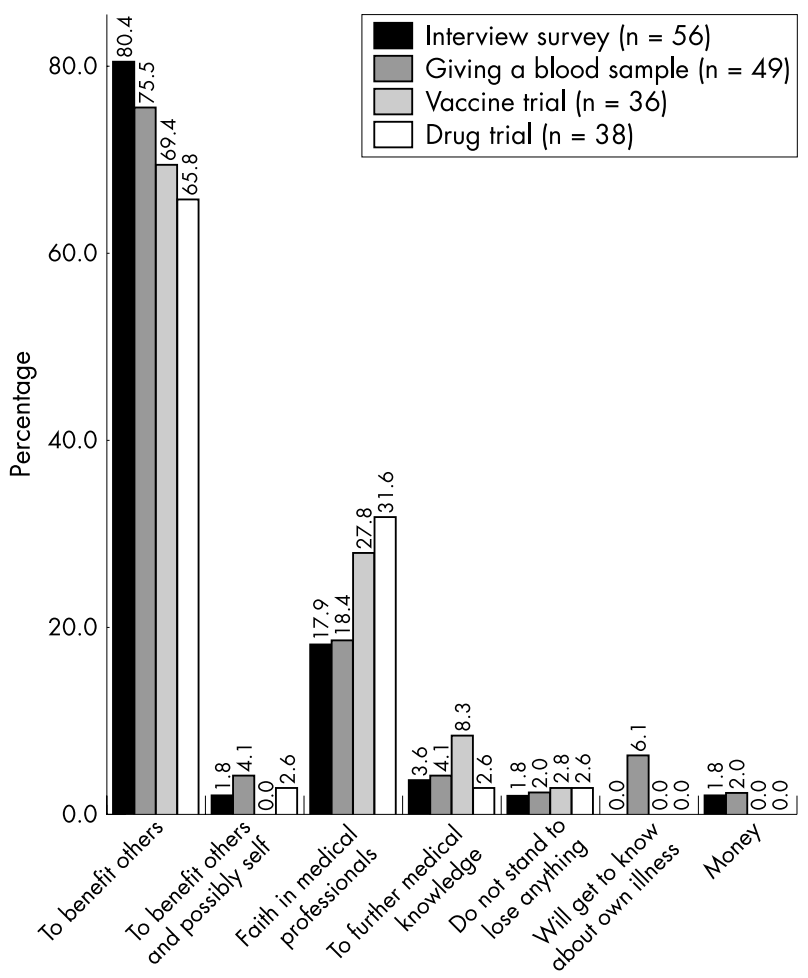

Figure 2 Reported reasons for own participation in research studies.
Table 1 Reasons for own non-participation in research studies

\begin{tabular}{|c|c|c|c|c|}
\hline Reason & $\begin{array}{l}\text { Interview } \\
\text { survey } \\
(n=1)\end{array}$ & $\begin{array}{l}\text { Giving a } \\
\text { blood } \\
\text { sample } \\
(n=8)\end{array}$ & $\begin{array}{l}\text { Vaccine } \\
\text { trial } \\
(n=21)\end{array}$ & $\begin{array}{l}\text { Drug } \\
\text { trial } \\
(n=19)\end{array}$ \\
\hline $\begin{array}{l}\text { Afraid/concern about } \\
\text { (unknown) side effects }\end{array}$ & $0(0.0)^{*}$ & $0(0.0)$ & $13(61.9)$ & 13168.4 \\
\hline $\begin{array}{l}\text { Am healthy/not unwell, so } \\
\text { why should I participate }\end{array}$ & $0(0.0)$ & $4(50.0)$ & $3(14.3)$ & $3(15.8$ \\
\hline $\begin{array}{l}\text { Never needed medical help } \\
\text { (so why contribute) }\end{array}$ & $1(100.0)$ & $1(12.5)$ & $1(4.8)$ & $1(5.3)$ \\
\hline $\begin{array}{l}\text { Have never had to do this } \\
\text { for myself let alone do it for } \\
\text { others }\end{array}$ & $0(0.0)$ & $0(0.0)$ & $1(4.8)$ & $1(5.3)$ \\
\hline Have less blood in the body & $0(0.0)$ & $2(25.0)$ & $0(0.0)$ & $0(0.0)$ \\
\hline Afraid of injections & $0(0.0)$ & $0(0.0)$ & $2(9.5)$ & $0(0.0)$ \\
\hline No reason & $0(0.0)$ & $1(12.5)$ & $1(4.8)$ & $1(5.3)$ \\
\hline
\end{tabular}

Would the subject's child be allowed to participate in the study?

On the whole, subjects were less willing to allow their children to participate than they were to do so themselves. One subject said, "We can volunteer ourselves, but not the children." The trend though, for their children's participation in the different mentioned interventions was similar (fig 1).

Who would decide if the subject's child could be enrolled?

Of the 50 men interviewed, 45 said that they would decide about whether their children should be enrolled or not. Three men left the decision solely to their fathers, one left it to both his parents, and one man said that he and his father would decide together.

Two of the seven women said they would decide for their children on their own. Two said that their mother-in-law would decide, one said her husband would decide, one woman needed to consult her parents, and another said that she and her husband would jointly decide about their child.

\section{Why would the child be allowed/not allowed to participate? \\ Allowed to participate}

The reasons why children would be allowed to participate were similar to those why subjects themselves would participate (fig 3). Altruism was the commonest reason followed by an implicit faith in the medical system.

\section{Not allowed to participate}

As with themselves, subjects were least willing to volunteer their children for vaccine or drug trials for fear of adverse effects (table 2). Many subjects were unwilling to allow their children to be "used for research". The other reasons for not allowing the children's participation are as stated in the table.

What information do the subjects feel they require before participating?

In response to a question about whether they would like any information before decision making about participation in any kind of research, of the 57 subjects, 35 (61.4\%) answered in the affirmative, $14(24.6 \%)$ said that they did not know what to ask, and $10(17.5 \%)$ said that they did not need any information as they trusted doctors implicitly and felt that doctors would not harm them. One of these subjects said, "We'll only take the new agent because doctors are telling us to. If they tell us to take a particular medicine, we will surely do so even if it is poisonous".

As seen from table 3, the information requested by the 35 respondents was most often about the disease that was being 


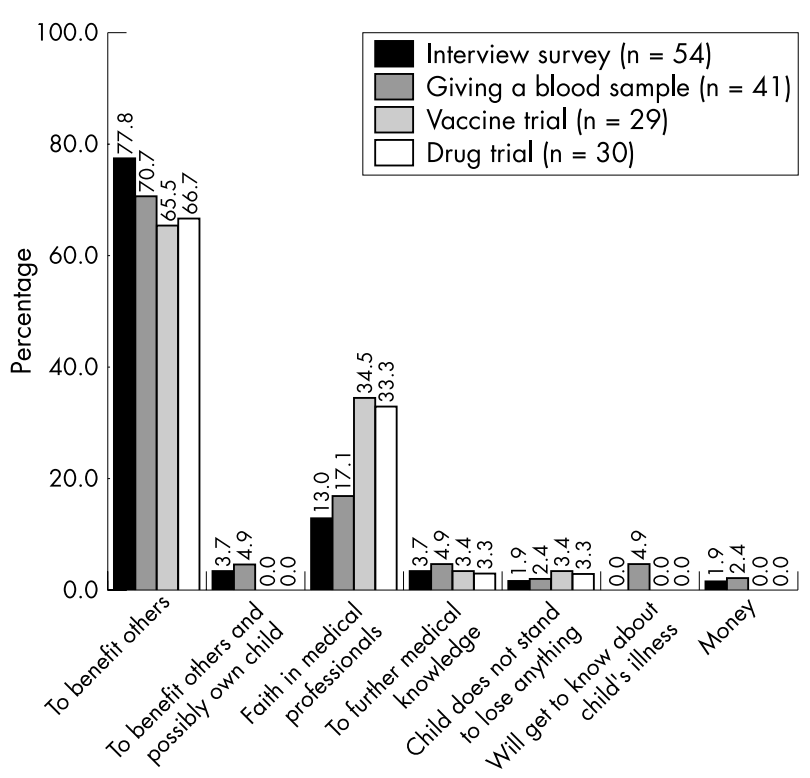

Figure 3 Reported reasons for allowing children's participation in research studies.

studied, followed by whether the researcher was from an authorised medical care giving institution, and the effects and adverse reactions to drugs and vaccines. Other information sought by these respondents is given in table 3 .

\section{DISCUSSION}

This study sought to determine how potential subjects for community based research in a developing world scenario would decide about their participation in such research.

In our setting, although most of the subjects ( 48 of 57, or $84.2 \%$ ) said they would decide about their participation on their own, only $36.8 \%$ (20 men and one woman) would make the decision completely independently. Of the 57 interviewed, $36(63.2 \%)$ reported that they would need to at least consult with other people (family, friends, or neighbours in the village). Beliefs about personhood, individual autonomy, and decision capacity are embedded within the social and cultural patterns of family ties and community obligations. ${ }^{6}$ It has often been suggested that the concept of an individual making a personal decision independent of the community is not common in cultures of the developing world. ${ }^{7}$ Religious, tribal, or community leaders, or the person's extended family play a significant role in decisions concerning health care and health research. ${ }^{8}$ In these communities, personhood is often defined by one's family, caste, village, or social group ${ }^{9}$ and therefore, decisions about consent are likely to be made at the level of the extended family, community, or village. In a situation like ours, where most of the villagers do take their own decisions but the decision making process is participatory, it would be desirable to give information about the proposed research work well in advance, so as to facilitate the local pattern of decision making. Information given at a clinic followed by immediate recruitment would be inappropriate.

Women in rural north India are less likely to be decision makers as women in this region have very little autonomy and tend to depend largely on men for health related decisions. ${ }^{10}$ Women tend to suffer from many disadvantages in social life. This includes controlled access to essential domains such as education, mobility, employment, property, income, and decision making. This occurs because the value system perceives women as a social category inferior to men in all aspects of social life. ${ }^{11}$ Of the seven women we interviewed only one who said she would decide about her
Table 2 Reasons for not allowing children's participation in research studies

\begin{tabular}{|c|c|c|c|}
\hline Reason & $\begin{array}{l}\text { Interview } \\
\text { survey } \\
(\mathrm{n}=3)\end{array}$ & $\begin{array}{l}\text { Giving a } \\
\text { blood } \\
\text { sample } \\
\text { (n=16) }\end{array}$ & $\begin{array}{ll}\text { Vaccine } & \text { Drug } \\
\text { trial trial } & \text { trial } \\
(n=28) & (n=27)\end{array}$ \\
\hline Afraid of (unknown) side effects & s0 $(0.0)^{*}$ & $0(0.0)$ & $16(57.1) 5(55.6)$ \\
\hline $\begin{array}{l}\text { Will not allow children to be } \\
\text { exposed to risk/used for } \\
\text { research }\end{array}$ & $2(66.7)$ & $6(37.5)$ & $6(21.4) 6(22.2)$ \\
\hline $\begin{array}{l}\text { Child healthy/not unwell, so } \\
\text { why should I allow participation }\end{array}$ & $0(0.0)$ & $5(31.3)$ & 4 (14.3) 4 (14.8) \\
\hline $\begin{array}{l}\text { Never needed medical help } \\
\text { (so why contribute) }\end{array}$ & $1(33.3)$ & $1(6.3)$ & $1(3.6) \quad 1(3.7)$ \\
\hline $\begin{array}{l}\text { A small child does not have } \\
\text { enough blood }\end{array}$ & $0(0.0)$ & $3(18.8)$ & $0(0.0) \quad 0(0.0)$ \\
\hline No reason & $0(0.0)$ & $1(6.3)$ & $1(3.6) \quad 1(3.7)$ \\
\hline
\end{tabular}

own participation independently. The remaining six (85.7\%) could decide only after consulting with their families/elders. Four of these six women would also not be able to decide for themselves and would abide by decisions taken by others (husband or mother-in-law). Women, in most rural Indian communities, especially north India, who have successfully reared children, especially sons, gain in power and status in the household (and community) as they and their children grow older. ${ }^{12}$ Elderly women as mothers-in-law wield considerable influence over the younger women in the household. Recruitment immediately following an explanation at antenatal clinics, postnatal clinics, or at maternal and child health clinics where women usually attend does not allow men (who are often the sole decision makers or play a major role in decision making about their wives or children) to contribute to the decision (about participation in research studies). Although the number of women interviewed in this study is not significant, most of them believed they would not decide for themselves independently. This situation would present a challenge to the application of Western ethical principles of informed consent, which require adults to be primary decision makers about their participation.

A similar scenario has been described in another part of the developing world, Uganda ${ }^{13}$ whereby Ugandan women would refuse to make a decision regarding their own or their children's participation in research without their partner's consent.

Participation was more forthcoming when non-invasive research using interview surveys was involved and less forthcoming when it meant giving a blood sample, administering a drug, or receiving a vaccine. Not having enough blood was an important indigenous fear when it came to

Table 3 Information required before participating in a community based study $(n=35)$

\begin{tabular}{ll}
\hline Information requested & Frequency (\%) \\
\hline What (disease) are you studying and why? & $28(80)$ \\
What authority do you have/where are you from? & $5(14.3)$ \\
Effects and side effects of drug/vaccine & $4(11.4)$ \\
Who is responsible/where can the person be found & $3(8.6)$ \\
in case of a side/adverse effect? & $2(5.7)$ \\
Would there be any gain from taking the drug/ & \\
vaccine? & $2(5.7)$ \\
Do you give an assurance that you will help me later & 2 in time of need if I cooperate with you in the trial? \\
Will participation be financially remunerative? & $1(2.9)$ \\
Will I be informed of illness if found in blood sample? & $1(2.9)$ \\
Will I be given treatment if a disease is found in my & $1(2.9)$ \\
blood sample? & \\
\hline Multiple responses possible, percentages total > $>100$. &
\end{tabular}


giving a blood sample. This perhaps stems from a deep rooted cultural perception in this region that equates the degree of one's wellbeing (absence of ill health) as being directly proportional to the volume of blood one possesses in one's body. This is also perhaps the reason why a relatively larger number of respondents (table 1) stated their non-participation if the study involved a blood sample. The fear of side effects was an important reason for non-participation in drug or vaccine trials. Children's participation in research was viewed less favourably than people's own participation. Children in this part of the world are often regarded as assets, or wealth, to fall back onto in one's old age. Parents would exercise utmost caution and were less willing to expose their children to "any risk" or be "used for research".

The main reported motivation for subjects volunteering themselves or their children for community based clinical research was altruism. Another important and perhaps alarming reason was an implicit faith in doctors-the doctor-patient relationship being a very paternal one in this part of the world, with major medical decisions being left exclusively in the hands of the physician with very little participation from the patient. ${ }^{14}$

Despite most subjects being unwilling to participate or volunteer their children for fear of unknown side effects, a significant 38.6\% (22 of 57) of respondents (fig 4) did not need any information as they trusted their doctors or did not know what information to ask for before deciding to consent. This lack of awareness about risks involved with participation puts the responsibility of the subjects knowing about the benefits and risks they might incur squarely on the researcher, in such a scenario. Only $61.4 \%$ of participants reportedly wanted information for decision making. It is worth noting that the information they requested was about the disease being researched and the reason for its selection. It is possible that those participating would make an informed choice depending on relative importance of the topic being researched to their community and individual perceived susceptibility. Surprisingly, only a small number of subjects $(8.8 \%)$ were concerned about safety and side effects. Some of the people's willingness to cooperate might result from the need for medical care associated with participation (table 3).

\section{CONCLUSIONS}

Our study provides evidence from a region of the Indian subcontinent for cultural variation in the process of giving

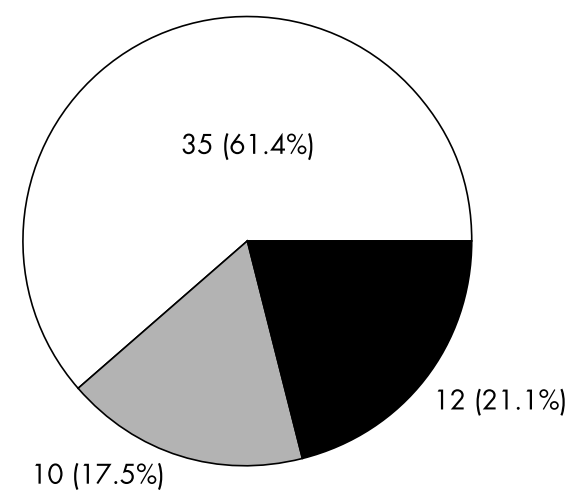

Do not know what information is to be asked Do not need any information as doctors are trusted implicitly

Need some information

Figure 4 Requirement of information for decision making concerning participation in community based research studies $(n=57)$. informed consent, the desire for information in the consent process, the degree of paternalism in the doctor-patient relationship, and the role of the family and community in the informed consent process. An extensive review on the sociocultural contexts for the ethics of clinical trials has been a part of the NHS R\&D Health Technology Assessment Programme. ${ }^{15}$

An important finding of our study was that the majority of the community interviewed could decide about participation only after discussing it with other community members. Only about a third of all respondents could take an exclusively independent, non-consultative decision. In the case of the few women interviewed, this proportion was even lowermost believed they would be unable to decide for themselves. However, given that women in our setting have a lower social status and lesser decision making rights, and the fact that the study captures the way men (the major decision makers in our setting) make decisions regarding participation in community based research, the study findings would be applicable to similar settings where men are predominant decision makers.

Another important fact which emerged was a significant implicit trust which part of the community had in the medical system, coupled with an ignorance of what information one might want to know before consenting to be part of a research study. Both these factors put an enormous ethical duty on the investigator researching in such a cultural setting. In this part of the world, the potential subject is from a family and community oriented culture, his/her normal decision making process involves his/her reference group, and exclusion of that group from that process damages the process. Related to this is the point that patients from cultures which value or expect paternalism, and place a high degree of systematic trust and reliance in the doctor's expertise, need to have this respected in the consent process. $^{15}$

The investigator, after disclosing in the most complete manner possible the risks a subject is likely to be exposed to by his participation, would require to seek informed consent unhurriedly, allow time for discussion with other members of the community, and be convinced that the responsibility for the decision lies with the potential subject him or herself. Persons who are vulnerable because of their sex or status in the local community (especially if the doctor-patient relationship is characterised by paternalism) need to be given considerable reassurances about their ability to refuse to participate and withdraw if they choose to. ${ }^{6}$

This is overall a very challenging responsibility: to obtain ethical informed consent from subjects who may be illiterate, but not unable to decide, ${ }^{16}$ speak a different language, do not share similar concepts of disease, perhaps have no prior concept of clinical research, and who identify themselves as members of their families, communities, or villages rather than as autonomous individuals.

Ethical principles of Western medicine on informed consent require all adults to be primary decision makers about their own participation. However, the relevance and applicability of Western principles of autonomy and individualism need to be contextualised to these settings.

It would be inappropriate in these parts of the world to overstress the individual's role in decision making. Value differences relevant to science and health in a multicultural world need to be built into the principles of informed consent. ${ }^{17}$ The notion that certain ethical principles are applicable cross culturally ${ }^{18}$ needs to be reconsidered. The emphasis of ethics in research needs to be shifted away from the professional viewpoint towards that of the lay community. ${ }^{15}$ 


\section{Authors' affiliations}

A DeCosta, Department of Pharmacology, All India Institute of Medical Sciences, New Delhi, India

N D'Souza, Nishat Manzil, Shamla Hills, Bhopal, Madhya Pradesh, India

S Krishnan, M S Chhabra, I Shihaam, All India Institute of Medical Sciences, New Delhi, India

K Goswami, Center for Community Medicine, All India Institute of Medical Sciences, New Delhi, India

\section{REFERENCES}

1 Christakis NA. Ethics are local: engaging cross-cultural variation in the ethics for clinical research. Soc Sci Med 1992;35:1079-91.

2 Barry M, Molyneux M. Ethical dilemmas in malaria drug and vaccine trials: a bioethical perspective. J Med Ethics 1992;18:189-92.

3 World Health Organization and the Council for International Organization of Medical Sciences. Proposed international guidelines for biomedical research involving human subjects. WHO, 1982.

4 lisselmuiden CB, Faden RR. Research and informed consent in Africaanother look. N Engl J Med 1997:326:830-3.

5 Center for Research in Rural and Industrial Development, Chandigarh \& International Institute for Population Sciences, Mumbai. National Family Health Survey 2. Haryana.

6 Marshall PA. The relevance of culture for informed consent in US-funded international health research in National Bioethics Advisory Commission,
Ethical and Policy Issues in International Research: Clinical Trials in Developing Countries. Bethesda, MD: National Bioethics Advisory Council, 2001

7 Taylor CE. Clinical trials and international health research. Am J Pub Health 1979:69:981-3.

8 Levine RJ. Informed consent: some challenges to the universal validity of the Western Model. Law Med Health Care 1991;19:207-13.

9 De Craemer W. A cross cultural perspective on personhood. Milbank Mem Fund Q Health Soc 1983;61:19-34.

10 Singh KK, Bloom SS, Tsui AO. Husbands' reproductive health knowledge, attitudes and behavior in Uttar Pradesh, India. Stud Fam Plan 1998;29:388-99.

11 Sharma KL. Social Stratification in India-issues and themes. New Delhi: Sage Publications, 1997.

12 Dasgupta M, Chen CL, Krishnan TN. Women's health in India: risk and vulnerability. Oxford: Oxford University Press, 1995

13 Love S, Okello D, Kawuma M. Research Bioethics in the Ugandan context: A programme summary. J Law Med Ethics 1996;24:47-53.

14 Quill TE, Brody H. Physician recommendations and patient autonomy: Finding a balance between Physician power and patient choice. Ann Intern Med 1996:125:763-9.

15 Ashcroft RE, Chadwick DW, Clark SRL, et al. Implications of socio-cultural contexts for ethics of clinical trials. Health Technol Assess 1997;1:1-65.

16 Ajayi OO. Taboos and Clinical Research in West Africa. J Med Ethics 1980;6:61-3.

17 Baker R. A theory of International Bioethics: Multiculturalism, Post modernism and the bankruptcy of Fundamentalism. Kennedy Inst Ethics $J$ 1998;8:101-32.

18 Beauchamp T. The mettle of moral fundamentalism: A reply to Robert Baker. Kennedy Inst Ethics J 1998;8:189-92. 